\title{
Improving Intelligent Systems: Specialization
}

\author{
Jesús A. Román, Sara Rodríguez, Juan M. Corchado \\ Departamento Informática y Automática. Universidad de Salamanca \\ Plaza de la Merced s/n, 37008, Salamanca, Spain \\ \{zjarg;srg; corchado\}@usal.es
}

\begin{abstract}
The specialization exists in biological systems and in human organizations, as a methodology to improve processes and optimize their aims. This specialization in artificial intelligent systems such as multi-agent systems, can improve their aims, depending on the type of specialization and the goals which they need to achieve. The enterprise networks are a collaboration model between companies which we can apply over these intelligent systems, so that, these systems can achieve more complex aims. Therefore, in this collaboration type, is necessary to consider their specialization type, and how they could collaborate to achieve aims, that by themselves would not be possible.
\end{abstract}

Keywords: multi-agent systems, intelligent systems; specialization; intelligent communities

\section{Introduction}

Many of the artificial intelligent systems try to emulate the operation of biological systems, which evolve to achieve their goals in the most efficient possible way (1) (2) (3). The human organizations within enterprise environments (4) (5) (6) are a type of biological systems, which pursue to maximize their benefits through organizational and specialization techniques, and through partnerships with other business environments. The assimilation of these organizational policies over artificial systems (7) (8) improves their efficiency with the introduction of features as specialization and collaboration between different systems which collaborate allowing achieve goals that, in an independent way, would be not possible. This methodology has been applied to improve the operation of a logistic system in a real company which works with two different type of software, and can not communicate between them. To do this, we have based in a previous works (9) (10) where Specialized Intelligent Communities are used. This paper is organized as follows. In section 2 the state of the art is introduced and the related work in biological and artificial systems. Section 3 analyzes the specialization in artificial systems. Section 4 introduces the case of study where the

adfa, p. 1, 2011.

(C) Springer-Verlag Berlin Heidelberg 2011 
concepts of specialization and cooperation in intelligent systems are applied. Finally, in section 5, are presented the conclusions.

\section{Related Work}

Specialization can be defined as the particular characteristic of an individual within a group. This specialization is present in all kinds of areas, from biological systems (1) (2) (3), to enterprise production systems (11) (12) (6), if it is taken as a mechanism to achieve greater efficiency, in the common aims of the group.

The specialization in biological systems has been taken as a reference in human organizations to improve their aims. According to R. Melinkoff the principle of specialization begins when the activities of each of the members of an organized group should be confined, as far as possible, to the execution of a single task (4). In human organizations, specialization is a feature relative to the workstation, internally (4), or the final product or service offered by that organization. This specialization aims to achieve greater efficiency in the products or services offered by the organization. However, productivity increases when there are synergies between different specialized organizations that collaborate to obtain an optimal yield on common production processes, such as the enterprise networks (12) (6).

In collaborative artificial systems, such as social multi-agent systems (13) (14) (15) (16) (8) (17) (18) (19) (20) (21), the specialization is an issue dealt with by several authors in works such as (22) (23) (24) (25) (26) (27) among others . This specialization aims to provide greater efficiency for the artificial system, so that there is an improvement in the achievement of its overall aims.

The idea of apply the specialization of human organizations to intelligent systems, such as multi-agent systems, through business networks methodology, would improve the efficiency of the system units, the aims of the system, and possible goals that would have to be achieved in collaboration with other systems. To achieve this adaptation are used Specialized Intelligent Communities (SIC) (9) (10) as a basis for the development of multi-agent systems, and distributed intelligent systems. These Intelligent Communities present the specialization as an internal feature to their constitution, being this feature very interesting in achieving our aims.

\section{$3 \quad$ Specialization in Intelligent Systems}

A complete classification of the types of specialization in cooperative artificial systems, and therefore in multi-agent systems, is given in (28), which suggests that the study of specialization in collaborative artificial systems has been approached from 
different perspectives depending on the approach that the authors have given their research. Example of these works are (29) (30) (31) (32) (26), among others.

Several authors in the literature, agree that the division of the objectives pursued by a group into specialized subtasks benefits the achieving these goals (33) (34) (35). However, the extrapolation of this specialization, from a point of view of a group of agents that collaborate atomically, in achieving broader goals is not still well defined.

The concept of enterprise network applied on artificial systems is introduced like Specialized Intelligent Communities (10). This type of systems are based in organizations and are fully autonomous. Among their features, they should be specialized, and they should have the ability to interact with each other to achieve overall objectives more complex, without losing their independence, being these features very important to achieve our aims.

\section{Development of a Logistic System Based on an Enterprise Network}

Often, computer systems which own businesses are generalists and do not allow to fully develop their business processes as they really are. Other times, exist custom developments which implement these business processes perfectly, however, the cost of these computer programs increases due to the time required to develop it. In both cases usually be the communications with other systems already running, a weak point, when is necessary to exchange data or extend functionalities.

In this case, there are no communications between two computer programs which belong to a real enterprise environment, therefore the principal aim is the development of this communication as a new functionality. This environment has the following characteristics:

The customer has two geographically separated locations, where in each one, are implemented different services. In the first one, are performed labors of production of livestock feed, and in the other one, is managed the logistic task. Both sites have a specific software to perform their activities, however the communication between them is not possible, and the management of logistics production is realized via phone and through emails and fax.

The proposed problem is the development of the data communications, from production site to logistics site because the time spent in this task is excessive. In addition, considering that there are several types of products, and in many cases, the final data are not correct because there are errors in shipping or in reception. Thus, is given the 
possibility that the correct information, is not delivered to the person responsible to perform the planning.

To solve this problem it is proposed a middleware system based on the architecture presented in the Specialized Intelligent Communities (SIC) (9) (10). These SIC are composed by a fixed structure composed by three entities, a coordinator, a planner and an executor, which they are assigned specific and specialized tasks, that working independently and they can collaborate as an enterprise network. This system consists of three SIC which are described below:

Specialized Intelligent Community in Data Capture: This SIC runs itself independently, and their work consists in receiving production data. To achieve this, it is accessed to the production database periodically, checking if there are new products ready for shipment from the factory. If so, the data is extracted and encoded into a JSON format (36) as shown in table 1, to be sent later to the SIC responsible of logistic.

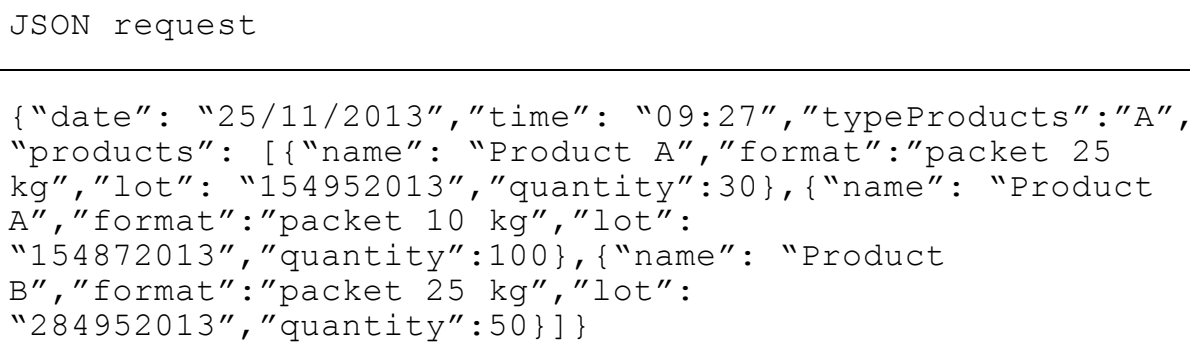

Table 1. Example of JSON data request

Specialized Intelligent Community in Logistic: Once received the notification and is verified the data integrity, a notification is send to the SIC of data capture. Subsequently, an analysis of these data is performed, and depending on the type of product and quantity, is loaded the information into the database of the software that manages the logistics, due to these features are considered for the distribution. For the estimation of priority to distribute the shipments, is used the expression given in 1 .

$$
P_{i=} \operatorname{Now}(t)-T_{R} T_{C}
$$

Where $\mathrm{P}_{\mathrm{i}}$ is the order priority, Now $(\mathrm{t})$ is the current date and time, $\mathrm{T}_{\mathrm{R}}$ is the moment when the order is placed by the end customer and $\mathrm{T}_{\mathrm{C}}$ is the type of client, that will 
change the weight of the order with values between 0 and 1 . Through this priority, is the software of logistic which automatically calculates the available vehicles in the selected route, and their size.

Specialized Intelligent Community in Incident Management: The SIC is responsible for managing incidents that may occur during the process of communication between them. In case there is no successful communication, the data will be processed again for a set period of attempts, and if not possible this transmission, it will generate an incidence and will notify via email to the responsible for the administration of the information systems, finally will paralyze sending information until the incidence is not solved. All transactions are recorded in a file in order to determine the fails that could have occurred.

Having described the functions of each SIC individually, the collaboration of these, determines the true objective pursued. Through this assimilation to a vertical enterprise network (6), in which each SIC provides its services, is achieved the final purpose, which is the communication between two independent applications. Asynchronously, can be requested the services of each SIC to obtain reports, highlighting they are distributed so that the computational resources required are reduced. As shown in figure 1, is the SIC of data capture which checks the database of the application of production to check for new products. From this moment the production data are sent in a JSON format that travels through HTTP + SSL to the SIC responsible of logistic which manage the load orders as efficiently as possible and automatically, decrementing considerably the processing time of the orders.

The benefit provided by the specialization in this problem is the simplicity of each component of the intelligent system and the future extensions which can be needed, can be easily implemented in the system. In addition, the services provided by the SIC can be requested by any device and from any programming language, which gives even more versatility in its performance. 


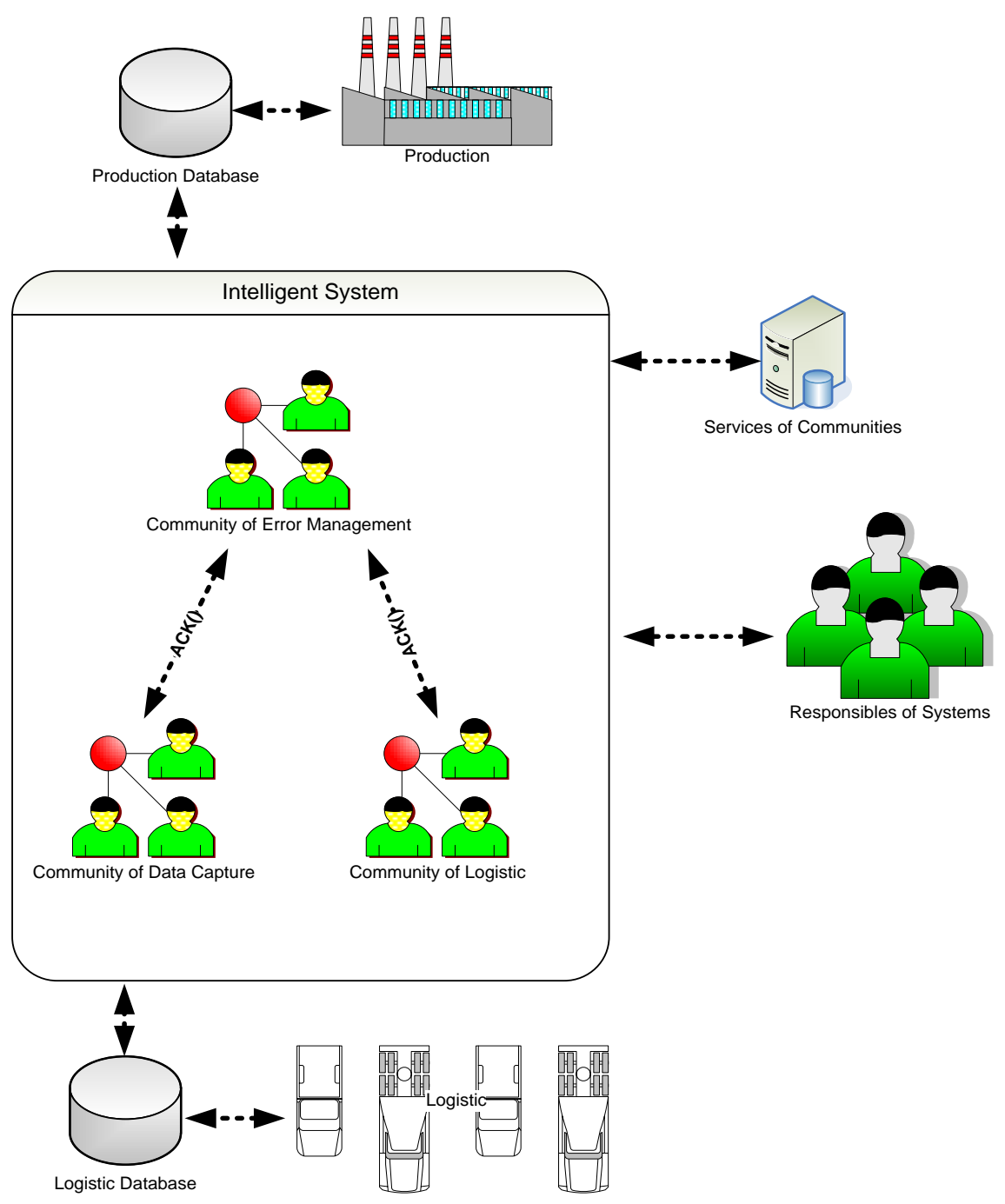

Fig. 1. Complete diagram of the system

The results obtained with the implementation of the system are completely satisfactory, having in account that the legacy system can not be replaced by a new system, because the system can reduce an important amount of time to specific jobs in the two sites of the company, and therefore use this time to improve the processing of orders. Another important feature is that the errors in the orders have been reduced significantly because the generation of orders are made by our system automatically with realtime data from the production system. Next, table 2 shows a summary of the results obtained with the implementation of the intelligent system. 


\begin{tabular}{|l|l|}
\hline Without Middleware & With Middleware \\
\hline Long time to process orders & Important reduction of time process orders \\
\hline Need several people to attend the orders & Automatic system to process orders \\
\hline Problems with the quantity of products & No errors in quantity of products \\
\hline Error control over the process & System to manage error control \\
\hline No information in real time & Information in real time \\
\hline
\end{tabular}

Table 2. Benefits of the intelligent system

\section{Conclusions}

We are aware that in large companies, the specialization in the jobs are an important feature (11) (37) (5), due to increases the productivity according specialization of workers. In an organization, the maximizing of their benefits due to the collaboration with other companies in the same field or complementary areas is a reality with the implementation of the enterprise networks (6) (12). In artificial systems is important to know and measure the type of specialization that have intelligent systems in order to optimize their performance. In addition, the assimilation of enterprise networks as a model of collaboration between companies, to intelligent systems, has allowed us to determine the possibility to fix more complicated goals that require a set of systems to complete their achievement.

The development of an intelligent system using Specialized Intelligent Communities as a basis for its development, allows the inclusion of specialization within the system, as an inherent feature of these entities, and their collaboration as enterprise networks allows to reach more complex targets. If we have in account that the computer programs, used by the company, can not be replaced, the result of the implementation of the communication on the system has been completely satisfactory because there is a significant savings in the time taken to process the information, from production management to logistic management. The reduction of errors in receiving process of products has been improved significantly due to its automation and data extraction directly from the production database. However, the overall system operation is not completely correct, because that the communications fail repeatedly due to the location of the sites and the signal provided by the companies providing Internet. This aspect can be improved because in any distributed system is necessary that the communications run properly in terms of availability and speed.

Acknowledgements. This work has been carried out by the project Sociedades $\mathrm{Hu}-$ mano-Agente: Inmersión, Adaptación y Simulación. TIN2012-36586-C03-03. Ministerio de Economía y Competitividad (Spain). Project co-financed with FEDER funds. 


\section{Bibliography}

1. Caste fate conflict in swarm-founding social hymenoptera: an inclusive fitness analysis. Wenseleers, T., Ratnieks, F. y Billen, J. 1, 2003, Evolutionary Biology, Vol. 16, págs. 647-658.

2. Bonabeau, E. y Theraulaz, G. Role and variability of response thresholds in the regulation of division of labour in insect societies. [ed.] J. Deneubourg \& J. Pasteels. Information processing in social insects. s.I. : Springer Verlag, 1999, págs. 141-163.

3. Ontogenetic development and the evolution of the worker caste in termites. Noirot, C y Pasteels, J. 1, 1987, Experientia, Vol. 43, págs. 851-860.

4. Melinkoff, R.V. La Estructura de la Organización. s.I. : Universidad de Venezuela, 1969.

5. Borisov, E.F., Zhamin, V.A. y Makarova, M. F. Diccionario de Economía Política. Barcelona : España, 1975.

6. Las redes empresariales y la dinámica de la empresa: aproximación teórica. Beccera, F. 32, 2008, INNOVAR. Revista de Ciencias Administrativas y Sociales, Vol. 18, págs. 27-45. 0121-5051.

7. Knowledge-based system to define context in commercial applications. $\mathbf{N}$. Sánchez, V. Fuentes, J. Carbó, J.M. Molina. Qingdao (Tsingtao) : s.n., 2007. 8th ACIS International Conference on Software Engineering, Artificial Intelligence, Networking, and Parallel/Distributed Computing (SNPD2007) and 3rd ACIS International Workshop on Self-Assembling Wireless Networks (SAWN2007). págs. 694-699.

8. Multi-agent system organization: An engineering perspective. Garijo, F., Gómes-Sanz, J.J., Pavón, J., Massonet, P. 2001. Pre-Proceeding of the 10th European Workshop on Modeling Autonomous Agents in a Multi-Agent World (MAAMAW'2001). 
9. Distributed and Specialized Agent Communities. Román, J.A., Rodríguez, S. y Corchado, J.M. Salamanca : s.n., 2013. Trends in Practical Applications of Agents and Multiagent Systems. Special Sessions of PAAMS 2013. Vol. 221, págs. 33-40.

10. SCODA para el Desarrollo de Sistemas Multiagente. Román, J.A., Tapia, D.I. y Corchado, J.M. 8, 2011, Revista Ibérica de Sistemas y Tecnologías de Información, págs. 25-38.

11. Smart Specialization a Possible Solution to the New Global Challenges. Rusu, M. 2013, Procedia Economics and Finance, Vol. 6, págs. 128-136.

12. An Organizational Concept for Collaborative Enterprise Networks. Baum, H. y Schütze, J. 2013. Procedia CIRP. Vol. 7, págs. 55-60.

13. Social-based planning model for multiagent systems. Rodríguez, S., de Paz, Y., Bajo, J., Corchado, J.M. 10, 2011, Expert Systems with Applications, Vol. 38, págs. 13005-13023.

14. CI Pinzón, J Bajo, JF De Paz, JM Corchado. S-MAS: An adaptive hierarchical distributed multi-agent architecture for blocking malicious SOAP messages within Web Services environments. Expert Systems with Applications 38 (5), 5486-5499.

15. DI Tapia, A Abraham, JM Corchado, RS Alonso. Agents and ambient intelligence: case studies. Journal of Ambient Intelligence and Humanized Computing 1 (2), 85-93. 2010.

16. DI Tapia, JF De Paz, S Rodríguez, J Bajo, JM Corchado. Multi-agent system for security control on industrial environments. International Transactions on System Science and Applications Journal 4 (3), pp. 222-226. 2008.

17. J Bajo, JF De Paz, S Rodríguez, A González. Multi-agent system to monitor oceanic environments. Integrated Computer-Aided Engineering 17 (2), 131-144. 2010. 
18. J Bajo, JM Corchado. Evaluation and monitoring of the air-sea interaction using a CBR-Agents approach. Case-Based Reasoning Research and Development, 50-62. 2005.

19. S Rodríguez, B Pérez-Lancho, JF De Paz, J Bajo, JM Corchado. Ovamah: Multiagent-based adaptive virtual organizations. Information Fusion, 2009. FUSION'09. 12th International Conference on, 990-997. 2009.

20. S Rodríguez, Y de Paz, J Bajo, JM Corchado. Social-based planning model for multiagent systems. Expert Systems with Applications 38 (10), 1300513023. 2011.

21. JM Corchado, J Bajo, JF De Paz, S Rodríguez. An execution time neuralCBR guidance assistant. Neurocomputing 72 (13), 2743-2753. 2009.

22. Learning signaling behaviours and specialization in cooperative agents. Murciano, A. y Millan, J. 1, 1997, Adaptative Behaviour, Vol. 5, págs. 5-28.

23. Emergent specialization in swarm systems. Li, L., Martinoli, A. y Mostafa, Y. Berlin : LNCS 2412. In H. Yin, N. Allinson, R. Freeman, J. Keane, \& S.

Hubbard (Eds.), 2002. Intelligent Data Engineering and Automated Learning Ideal. págs. 261-266.

24. Emergence of Specialization from Global Optimizing Evolution in a Multiagent Systems. Lei, C, y otros, y otros. s.I. : In Shi et al. (Eds.), 2007. ICCS Part IV. págs. 98-105.

25. The Impact of Vertical Specialization on Hierarchical Multi-Agent Systems. Okamoto, S., Scerri, P. y Sycara, K. 2008. Proceedings of the Twenty-Third AAAI Conference on Artificial Intelligence.

26. Specialization analysis of embodied evolution for robotic collective tasks. Trueba, P., y otros, y otros. 2013, Robotics and Autonomous Systems, Vol. 61, págs. 682-693.

27. Costs and benefits of behavioral specialization. Brutschy, A., y otros, y otros. 2012, Robotics and Autonomous Systems, Vol. 60, págs. 1408-1420. 
28. Emergent specialization in biologically inspired collective behavior systems. Nitschke, G., Schut, M. y Eiben, A. 2007, Intelligent Complex Adaptive Systems, págs. 100-140.

29. The legion system: A novel approach to evolving heterogeneity for collective problem solving. Bongard, J. Edinburgh : Springer-Verlag, 2000. Proceedings of eurogp-2000. págs. 16-28.

30. Towards collaborative and adversarial learning: $A$ case study in robotic soccer. Stone, P. y Veloso, M. 1, 2002, Evolution and learning in multi-agent systems, Vol. 48, págs. 83-104.

31. Evolving keep-away soccer players through task decomposition.

Whiteson, S., y otros, y otros. Chicago, USA : AAAI Press., 2003. Proceeding of the genetic and evolutionary computation conference. págs. 356-368.

32. Competing sample sizes for the co-evolution of heterogeneous agents. Blumenthal, J. y Parker, G. Sendai, Japan : IEEE Press., 2004. Proceedings of the 2004 ieee/rsj international conference on intelligent robots and systems. págs. 1438-1443.

33. Arkin, R. Behavior based robotics. Cambridge, USA : MIT Press, 1998.

34. Behavior-based formation control for multi-robot teams. Arkin, R. y Balch, T. 6, 1999, IEEE Transactions on Robotics and Automation, Vol. 14, págs. 926-939.

35. Measuring robot group diversity. Balch, T. Natick : In T. Balch \& E. Parker (Eds.), 2002. Robot teams: From diversity to polymorphism. págs. 93-135.

36. ecma. The JSON Data Interchange Format. Starndard ecma-404. 2013.

37. Arruñada, B. Economía de la Empresa: Un enfoque contractual.

Barcelona : Ariel, 1990. 